\title{
CONSIDERAÇÕES SOBRE O OFÍCIO DE DIRIGIR ÔNIBUS NO BRASIL: UMA REVISÃO DE LITERATURA
}

Thiago Drumond Moraes

Universidade Federal do Espírito Santo

Katia Santorum

Universidade do Estado do Rio de Janeiro

Fátima Valéria Belo de Souza

Universidade do Estado do Rio de Janeiro

Laís Rocha Ávila

Universidade Federal do Espírito Santo

Stefane Stolze Vieira

Universidade Federal do Espírito Santo

\begin{abstract}
Resumo
Os efeitos do ofício de dirigir ônibus para a saúde dos condutores desses veículos têm sido investigados em estudos de abrangência nacional. Para contribuir no aprofundamento desse objeto de estudo, realizamos uma revisão de pesquisas nacionais sobre esse ofício, objetivando investigar processos de saúde-doença e subjetivação, delimitando as buscas entre 2000 a 2012, mediante verificação temática. Da análise das publicações configuramos dois eixos de análise: os efeitos desse ofício na saúde dos motoristas de ônibus e as condições e organização desse trabalho. A pesquisa foi realizada sob a abordagem teórica da Ergonomia da Atividade francófona e orientada pela perspectiva da Ergologia. As dimensões físicas da saúde são mais pesquisadas que as psicológicas. Concluímos que, a despeito de se investigar a saúde de trabalhadores, suas condições de trabalho e sua atividade não são suficientemente consideradas: propomos caminhos para novos estudos, sobretudo, referentes à atividade do trabalho, abordando-a, inclusive, em sua positividade.
\end{abstract}

Palavras-chave: atividade de trabalho; motoristas de ônibus; saúde; saúde mental; subjetividade.

\section{CONSIDERATIONS ON THE PROFESSION OF BUS DRIVER IN BRAZIL: A LITERATURE REVIEW}

\begin{abstract}
The effects of driving buses craft to the health of drivers have been investigated in nationwide Brazilian studies. To deepen of this object of study, we conducted a review of Brazilian researches on this profession, to investigate the health-disease and subjectivation processes, from 2000 to 2012 by thematic verification. From this research, we draw two analysis axes: the effects of this profession on health of bus drivers and its conditions and organization. The survey was conducted under theoretical approach of Ergonomics of Francophone activity and it was also guided by the prospect of Ergology. Physical dimensions of health are more researched than psychological ones. We conclude that, in spite of investigating the health of workers, their working conditions and activity are not sufficiently considered: we propose ways to new studies, especially regarding work activity, approaching including its positivity. keywords: work activity; bus drivers; health; mental health; subjectivity.
\end{abstract}




\title{
CONSIDERACIONES SOBRE EL OFICIO DE CONDUCCIÓN DE AUTOBUSES EN BRASIL: UNA REVISIÓN DE LITERATURA
}

\begin{abstract}
Resumen
Los efectos del trabajo de conducción de autobuses para la salud de sus conductores se han investigados en estudios brasileños. Para profundizar el estudio, realizamos una revisión de pesquisas brasileñas sobre este oficio, para investigar procesos de saludenfermedad y subjetivación, desde 2000 a 2012, por verificación temática, llegando a dos ángulos: los efectos de esa actividad sobre la salud de eses trabajadores y las condiciones y organización del trabajo. La encuesta se basó en el enfoque teórico de la Ergonomía, de la Actividad de habla francesa y fue guiada por la perspectiva de la Ergología. Las dimensiones físicas de salud son más investigadas que las psicológicas. Concluimos que, aunque la investigación sobre la salud de los trabajadores, sus condiciones de trabajo y actividad no están suficientemente consideradas: proponemos nuevos estudios, especialmente sobre actividad laboral, incluyendo su positividad.

Palabras clave: actividad laboral; conductores de autobús; salud; salud mental; subjetividad.
\end{abstract}

\section{INTRODUÇÃO}

Mais da metade da população utiliza transporte coletivo urbano diariamente, no Brasil (Viegas \& Oliveira, 2006), sendo o ônibus o veículo mais usado. É nesse contexto que se insere uma das profissões que mais movimentam e se movimentam pelos caminhos e descaminhos das cidades: a condução de transporte rodoviário coletivo. Nosso interesse particular se volta para o motorista de ônibus, condutor dos passageiros pelas vias das cidades. Interessa-nos uma aproximação a esse ofício, fundamental na dinâmica das metrópoles, na circulação das gentes, na vida econômica, social e urbana. Resulta daí a importância dos motoristas de ônibus, em meio às exigências temporais e de segurança, e à gestão do trabalho desses profissionais. Por sua vez, tal gestão é exercida pelas empresas, pelo Estado e pelos próprios profissionais, sendo um desafio complexo e frequentemente contraditório, produzindo efeitos na saúde e subjetividade desses trabalhadores. Revisões de estudos internacionais assinalam alguns desses efeitos (Junior, 2003; Rosenbloom, 2011). Pesquisas nacionais também investigam a temática, embora careçam revisões de publicações dos últimos anos.

Buscando contribuir na superação dessa defasagem, realizamos uma revisão de literatura das pesquisas brasileiras que investigaram os processos saúde-doença e de subjetivação no ofício de dirigir ônibus no país. Para tanto, empreendemos uma análise crítica das publicações científicas, procurando evidenciar as relações entre os processos saúde-doença e de subjetivação e o trabalho dos condutores, as concepções de saúde-doença subjacentes a essas publicações e as lacunas existentes para serem preenchidas por trabalhos futuros. 


\section{A CAIXA DE FERRAMENTAS: ASPECTOS TEÓRICO-METODOLÓGICOS}

Esta revisão de literatura foi realizada por meio da busca e análise de artigos científicos de pesquisas brasileiras publicados entre os anos de 2000 a 2012 em revistas nacionais e internacionais e indexadas nas bases de dados Scielo, BVS Salud, CAPES, IndexPsi, Lilacs, Medline e Google Acadêmico. Para tanto, utilizamos as seguintes palavras-chave, tanto em português quanto em inglês, nas consultas às bases de dados: (motoristas OR condutores) AND (ônibus OR transporte coletivo) OR (rodoviários) AND (condições de trabalho OR saúde mental OR subjetividade OR saúde), sendo estas localizadas em qualquer local do artigo. Quando disponível na base de dados, restringimos as buscas por meio do termo "Brasil/Brazil" na opção afiliação dos autores. Visando ampliar nossa análise, recorremos às referências bibliográficas dos textos encontrados, na expectativa de inserir na revisão estudos que poderiam não ter sido encontrados por meio da busca inicial em função de uso de descritores insuficientes ou por serem textos não indexados nas bases consultadas.

Após a leitura dos títulos e/ou resumos, e exclusão dos estudos que não investigavam o trabalho dos motoristas de ônibus, selecionamos 59 (cinquenta e nove) publicações que foram integralmente lidas e analisadas. A análise consistiu-se em uma caracterização geral dos artigos na qual obtivemos as informações sobre o foco principal dos estudos realizados sobre essa temática e as metodologias utilizadas na produção de conhecimentos publicados. Em seguida, empreendemos uma análise descritiva e temática do conteúdo do artigo, utilizando tanto categorias previamente definidas - ano de publicação, teorias de base, tipos de instrumentos de investigação, etc. - quanto por meio da composição de categorias emergidas a partir da leitura dos textos. Neste caso, extraímos duas grandes linhas temáticas, a saber: (i) os efeitos na saúde dos motoristas de ônibus; e (ii) as dimensões do trabalho desses profissionais.

A partir da análise de conteúdo, analisamos os resultados dessa revisão a partir do ponto de vista teórico da Ergonomia da Atividade francófona e da Ergologia (Falzon, 2007; Guérin et al, 2001; Schwartz \& Durrive, 2010). Tomando por base esse ponto de vista, dialogamos com os artigos, buscando compreender: (i) as concepções de saúde que nortearam as abordagens das pesquisas, bem como (ii) os possíveis efeitos dessas concepções, tanto nos estudos, quanto na aplicação desses conhecimentos na realidade. Por conseguinte, observamos algumas lacunas no conhecimento científico que verificamos necessárias serem solucionadas.

\section{RESULTADOS}

Seguindo o modelo geral das condições e consequências do trabalho, distinguimos, nos resultados, os seguintes dois grandes eixos de estudos nas 
pesquisas realizadas: (i) o eixo dos efeitos do trabalho na saúde; e (ii) o eixo da descrição das demais dimensões do trabalho, caracterizando as condições e atividade de trabalho dos motoristas de ônibus. No primeiro eixo, encontram-se pesquisas que privilegiam a investigação da morbimortalidade e acidentes de trabalho. No segundo, investigações sobre a atividade de trabalho, e a organização e as condições de trabalho, dentre as quais se destaca a violência.

Nesse sentido, embora tal divisão seja mais evidente em alguns textos, em outros ela não é possível de ser realizada, razão pela qual, algumas pesquisas se encontram em mais de um lugar. Privilegiamos, aqui, as análises qualitativas e crítica das pesquisas, muito embora tenhamos realizado alguma contabilização que poderá contribuir para ilustrar o quadro das pesquisas nacionais sobre o tema.

\section{Eixo 1: Atento aos sinais - efeitos do trabalho: morbimortalidade}

A maior parte dos artigos publicados dedica-se à identificação de prevalência de agravos relacionados ao trabalho, sejam eles adoecimento ou acidentes. Comparativamente aos demais, os aspectos biológicos da saúde desses profissionais vêm recebendo mais atenção, tendo destaque estudos que investigam: doenças cardiovasculares, perdas auditivas induzidas por ruídos (pair) e dores osteomusculares.

\section{Doenças cardiovasculares}

As doenças cardiovasculares (DCV) foram investigadas em estudos epidemiológicos que apontaram alta prevalência de trabalhadores apresentando fatores de risco dessa patologia: em um dos estudos, verificou-se que $77,5 \%$ dos trabalhadores apresentavam índice de massa corporal (IMC) classificados como sobrepeso e obesos, $18,8 \%$ apresentavam circunferência abdominal acima de $102 \mathrm{~cm}$, e mais de um terço apresentava hipertensão arterial diastólica, hipercolesterolemia e hipertrigliceridemia (Hirata et al., 2012). Tais resultados são mais significativos do que os verificados no estudo de Corrêa Filho et al. (2002), no qual, 13,2\% da população pesquisada apresentou hipertensão.

Também foram investigados fatores de risco cardiovasculares (Alquimim, Barral, Gomes, \& Rezende, 2012; Benvegnú, Fassa, Facchini, \& Breitenbach, 2008; Hirata et al., 2012; Landim \& Victor, 2006; G. N. Moraes \& Fayh, 2011; Souza \& Silva, 2006b, 2006c), nos quais, a idade do trabalhador e o nível de aumento do IMC foram as principais variáveis relacionadas a essas patologias (M. M. Costa et al., 2011). Inclusive, foram encontradas associações consideráveis com os seguintes aspectos: colesterol total, pressão arterial, sedentarismo, história familiar, problemas psiquiátricos menores, consumo de gordura animal, dentre outros (Chaves et al., 2008), bem como, concernentes a pouca quantidade de sono e hiper-homocisteinemia (P. J. Martins et al., 2003). Vale ressaltar, no entanto, que, conforme demonstrado no estudo de Chaves et 
al. (2008), parte dos resultados tem, como base, a informação dos próprios trabalhadores, o que pode ser considerado um viés nos procedimentos de análise, influindo nos resultados.

Dentre os fatores de risco, os relacionados a hábitos de vida, como sedentarismo e alimentação inadequada, são mais investigados. Assim, é possível que, em razão disso, sejam verificadas mais correlações entre DCV e hábitos e estilos de vida. Ainda acerca desse contexto, alguns estudos demonstraram que tais hábitos estão associados à atividade profissional, em função da limitação que a jornada de trabalho impõe à prática regular de hábitos mais saudáveis (Faria, Amorim, \& Vancea, 2007; P. J. Martins et al., 2003). Por sua vez, foi verificada a mudança de estilo de vida dessa população, após ingresso na profissão, tendo sido esta evidenciada pelos seguintes aspectos: aumento de peso, diminuição da atividade física, má alimentação e maior risco de desenvolver problemas de saúde (Faria et al., 2007). Por outro lado, determinados artigos apenas indicam que a prevalência de obesidade aumenta significativamente com a idade, sem terem sido investigadas, nesses estudos, possíveis correlações com aspectos concernentes ao trabalho (M. M. Costa et al., 2011).

Note-se que pesquisas também demonstraram que estudos epidemiológicos sobre DCV, nessa população, não indicaram viés de seleção na amostragem - viés esse que poderia ocorrer, já que, quando um estudo é empreendido, os afastados por motivo de doença não seriam pesquisados, influenciando, tal fato, nos resultados (Souza \& Silva, 2006a). Esses mesmos autores demonstraram, no entanto, ser possível haver um outro tipo de seleção, mais perversa, em exercício nessa população (Souza \& Silva, 2005). Partindo-se do estudo da influência da hipertensão arterial sistêmica (HAS) em exames admissionais e aposentadorias precoces em motoristas de ônibus, foi verificado que a prevalência de HAS, considerando apenas os profissionais contratados e em atividade, diminuiu com a idade, sugerindo que há seleção de indivíduos saudáveis em diversos momentos: seja na contratação, no incentivo à aposentadoria ou na demissão dos considerados hipertensos. Trata-se, portanto, de um constante processo de seleção de indivíduos saudáveis: desde a fase de contratação, e continuando esse monitoramento com o objetivo da manutenção de, apenas, trabalhadores saudáveis no exercício desse ofício, no qual, tão somente os mais resistentes permanecem, ao longo dos anos, nessa atividade profissional.

\section{Perda auditiva induzida por ruídos (pair)}

Os estudos sobre a pair (Cepinho, Corrêa, \& Bernardi, 2003; Corrêa Filho et al., 2002; Freitas \& Nakamura, 2003; Hirata et al., 2012; Lacerda, Figueiredo, Neto, \& Marques, 2010; A. L. Martins, Alvarenga, Bevilacqua, \& Filho, 2001; A. S. Santos \& Júnior, 2009; L. F. Silva \& Mendes, 2005; Siviero, Fernandes, Lima, 
Santoni, \& Bernardi, 2005) assinalam que, além da alta prevalência dentre os profissionais pesquisados (variando entre $12 \%$ e $70 \%$ nas amostras), as frequências audiométricas, nas quais se observa maior comprometimento para a perda auditiva, encontra-se entre $4000 \mathrm{~Hz}$ e $6000 \mathrm{~Hz}$. Há, ainda, estudos demonstrando que tais perdas são bilaterais, enquanto que, em outros, seriam unilaterais, destacando aqui perdas unilaterais com ocorrências tanto no ouvido direito, quanto no esquerdo. As principais variáveis relacionadas ao agravo foram: elevação da idade e do nível de ruído, sendo encontradas também associações significativas no tocante: ao tempo de atuação na empresa, à exposição à vibração do corpo inteiro ( $\mathrm{VCI}$ ), à carga horária de trabalho, ao histórico de diabetes e ao contato prévio com metais pesados. Os estudos sobre a pair investigam, mais frequentemente, como variáveis independentes, os fatores relacionados ao trabalho, tais como: nível de ruído, intensidade da vibração, duração da jornada e tempo de atuação na profissão.

\section{Dores osteomusculares}

Estudos a respeito das dores osteomusculares são, de maneira geral, conduzidos por autores da área de Fisioterapia. Neto, Barreto, Sá e Maini (2008) demonstraram que a prevalência de lombalgia, em motoristas de ônibus de turismo e de coletivos urbanos, foi relativamente baixa $(3,8 \%$ e $10,5 \%$, respectivamente). Em outro estudo, ficou demonstrado que a dor, na coluna vertebral, é mais frequente entre motoristas de ônibus do que entre bombeiros militares (Queiroga \& Ferreira, 2005). Por sua vez, a pesquisa realizada por Guterres, Duarte, Siqueira e Silva (2011) demonstrou existir associação entre dor nas costas e as seguintes variáveis: a idade, a não realização de atividade física, o trabalhar mais de seis horas por dia, o tempo de desempenho da função e o possuir outra atividade profissional. Macedo e Battistella (2007) verificaram o impacto da lombalgia na qualidade de vida desses profissionais, que se sentem esgotados e cansados, sem vontade para realizar suas atividades pessoais e profissionais, além de possuírem uma visão negativa a respeito de sua saúde atual e futura.

De modo distinto, outras pesquisas não encontraram relação entre: lombalgia, fatores psicossociais (tendência à depressão, sentimento de tristeza, ansiedade, baixa educação e insatisfação no trabalho) e horas de trabalho na postura sentada (Bréder, Dantas, Silva, \& Barbosa, 2006; Bréder, Oliveira, Dantas, \& Silva, 2006), embora se observasse que as pessoas com dor tendiam a estar mais insatisfeitas com o trabalho e a mostrarem tendências mais depressivas. Estudos experimentais demonstraram, ainda, que o uso de um apoio para a coluna lombar, em motoristas de ônibus, pode contribuir para a diminuição e centralização da dor (Câmara, Bevilaqua, \& Moraes, 2008), bem como que exercícios físicos diminuem significativamente a intensidade das dores (Zavanela et al., 2012). 
Nesse contexto, um estudo investigou, inclusive, a relação entre sintomas de distúrbios osteomusculares e as variáveis jornada de trabalho, nível de atividade física e estado nutricional de motoristas e cobradores, não encontrando associações estatisticamente significativas nessa amostra (Carneiro, Coqueiro, Freire, \& Barbosa, 2007). Portanto, diferentemente dos agravos já mencionados, existe uma menor homogeneidade nos resultados entre as pesquisas sobre lombalgia, sobretudo no atinente às correlações com fatores relacionados ao trabalho, verificando-se necessidade de pesquisas com maiores amostras populacionais.

\section{Distúrbios do sono}

Tendo sido objeto de pesquisas realizadas principalmente entre motoristas de ônibus interestadual, os distúrbios do sono tiveram, dentre as principais queixas relacionadas ao sono para esses profissionais, os seguintes aspectos: fadiga física e mental, insônia, sonolência e irritabilidade (Mello et al., 2000), podendo ser agravadas pela síndrome da apneia obstrutiva do sono (AOS), cuja prevalência de fatores de risco é alta - IMC, alimentação inadequada e sedentarismo -, sendo correlacionadas aos seguintes fatores: o sono ao dirigir, o envolvimento em acidentes e a menor atenção concentrada e difusa (Viegas \& Oliveira, 2006). Em estudo sobre qualidade do sono, diurno e noturno, em motoristas que trabalham em turnos (E. H. R. Santos et al., 2004), os pesquisadores identificaram que o sono diurno tende a ser mais curto $e$ fragmentado e que, mesmo após sete horas de sono, noturno ou diurno, os motoristas permanecem sonolentos, sugerindo ser o esgotamento mental de tal intensidade que afeta, de maneira negativa, o sono. Esses dados demonstram relações entre: trabalho em turno, distúrbios do sono e aumento do nível de homocisteína no sangue (P. J. Martins et al., 2003).

\section{Transtornos mentais e subjetividade}

Os problemas de saúde supracitados caracterizam-se, predominantemente, como transtornos que envolvem, de maneira mais significativa, as dimensões físicas da saúde. Por outro lado, revisões internacionais demonstram efeitos psicológicos do trabalho nos transportes terrestres, sobretudo por sua relação com o trânsito (Ledesma, Peltzer, \& Poó, 2008; Rosenbloom, 2011). Ainda, de acordo com a Revisão de Literatura, poucas pesquisas brasileiras se dedicaram à investigação das dimensões psíquicas da saúde dos motoristas de ônibus.

Nesse contexto, Almeida (2010) verificou que $85 \%$ dos motoristas de ônibus, de sua pequena amostra, apresentaram sintomas indicadores de estresse, sendo os fatores financeiro, sexual e profissional analisados como os estressores mais comuns. Gianasi e Borges (2009), investigando a relação entre a síndrome de Burnout e as fontes de desgaste físico-emocional entre motoristas 
e cobradores, apresentaram prevalência de sintomas indicativos da síndrome em $41,4 \%$ da amostra, sendo que em $13 \%$, foi verificado em nível máximo. A síndrome correlacionou-se com conflitos de valores e ausência de equidade nas relações com a organização, sugerindo problemas organizacionais e de gestão na origem de tal transtorno.

Demonstrou-se, alhures, que $89 \%$ dos trabalhadores de uma empresa de transporte coletivo pesquisada apresentaram boa ou ótima percepção do conceito de capacidade para o trabalho (Sampaio, Coelho, Barbosa, Mancini, \& Parreira, 2009). Entretanto, alguns trabalhadores se referiram a problemas que afetam suas capacidades para o trabalho, tais como: violência, ambiente de trabalho impróprio, suporte social frágil, relacionamentos interpessoais conflituosos no trabalho, problemas no desenvolvimento de carreira, organização do trabalho inadequada e problemas em relação ao estilo gerencial. Em outra pesquisa, verificou-se que os sentidos do trabalho - associados à realização de um sonho, ao sustento pessoal e familiar e ao status conferido por ser motorista - eram afetados pelo afastamento por problemas de saúde mental (Gonçalves \& Buaes, 2011). Os sentimentos relatados a respeito do afastamento são de inutilidade, incapacidade, tristeza, fragilidade e insegurança, dando visibilidade ao lugar que o trabalho ocupa na vida desses profissionais. Esta, diferentemente das outras pesquisas citadas, sugere que a profissão produz efeitos positivos na vida dos trabalhadores.

\section{Outros agravos e condições gerais de saúde}

Em estudo de Balbinot e Tamagna (2002), sobre a transmissibilidade da vibração em bancos de motoristas de ônibus, foi verificado que a jornada de oito horas diárias é potencialmente prejudicial à saúde desses profissionais. Por sua vez, outras pesquisas investigaram queixas de saúde de maneira ampla. Em Neri, Soares, e Soares (2005), via dados da Pesquisa Nacional por Amostra de Domicílios (PNAD) de 1998, comparou-se as condições de saúde dos rodoviários com as dos ocupados em outros setores nos Estados: foi verificado ser $32 \%$ menor a chance dos profissionais pesquisados considerarem sua saúde "normal" vis-à-vis profissionais de outros setores, sugerindo desempenharem um trabalho com maior exigência à saúde.

Por sua vez, L. B. Costa, Koyama, Minuci e Fischer (2003) associaram as condições de trabalho e os sintomas de morbidade autodeclaradas, verificandose ligações entre os seguintes aspectos: obesidade e idade; extensão da jornada de trabalho e número de pausas para descanso; dores osteomusculares e trepidação, banco sem ajuste vertical, falta de apoio anatômico para as costas, inexistência da prática de esporte, idade; problemas gastrointestinais e medo de assalto no ônibus; perda de audição e presença de muito ruído; problemas de sono e medo de acidente. Por outro lado, o estresse estaria relacionado às 
variáveis: medo de acidente e de assalto, extensão da jornada e horário alternante ou irregular.

Por fim, uma pesquisa experimental sobre formação profissional, nesses casos, demonstrou que exercícios para condicionamento físico, resistência e flexibilidade, desde que realizados por 24 semanas, acarretaram em redução significativa, em comparação com o grupo-controle, da pressão arterial, da percepção de dor, do absenteísmo e do aumento da flexibilidade e fortalecimento muscular (Zavanela et al., 2012), sugerindo que exercícios físicos, sendo mais enfocados na atividade profissional, reduzem, em decorrência, os problemas de saúde e o absenteísmo.

\section{Acidentes de Trabalho}

Destacamos os acidentes, dentre as demais morbidades, dada sua relevância, considerando o quadro geral dos transportes terrestres. Verificamos serem escassos os estudos acerca dos acidentes envolvendo motoristas de ônibus: encontramos apenas dois. Em um deles, são investigados indicadores psicossociais relacionados a acidentes de trânsito, envolvendo motoristas de ônibus, na cidade de Natal-RN (Oliveira \& Pinheiro, 2007), no qual, os autores assinalam que os acidentes se relacionam a situações que, potencialmente, intensificam a carga mental do trabalho - preocupações com o dirigir atrasado, com o sono e com problemas familiares, bem como as reclamações de passageiros - e as políticas das organizações empregadoras - número médio de horas extras trabalhadas no mês e o trabalhar durante as férias.

Outro estudo, com base em acidentes registrados entre 1997 e 1999, verificados em Comunicação de Acidentes de Trabalho cadastrados no INSS de São Paulo, identifica os motoristas de ônibus, em terceiro lugar, dentre os que mais se envolveram em acidentes, no período estudado, sendo esses, em sua maioria, casados e na faixa etária de 35-45 anos (Teixeira \& Fischer, 2008). Os acidentes-tipos mais comuns entre esses profissionais foram: quedas dos ônibus, esmagamentos e choques/colisões. Os acidentes de trajeto mais frequentemente verificados foram: quedas do motorista em via pública, quedas dos ônibus e choques/colisões. As doenças relacionadas ao trabalho identificadas foram: surdez, estresse, traumatismos ou lesões, acarretando, principalmente, invalidez, incapacidade temporária e óbito, respectivamente. Vale salientar que nenhuma das pesquisas verificadas investigou efeitos dos acidentes na vida dos usuários de transportes coletivos e no trânsito, de um modo geral, sendo essa uma possível linha de investigação futura.

EIXO 2: Condições e organização do trabalho dos motoristas de ônibus: a saúde pede passagem

Além da identificação de agravos concernentes à saúde desses trabalhadores, determinadas pesquisas buscaram analisar os fatores de 
adoecimento relacionados à perda da capacidade laborativa. Destacam-se, em muitas investigações, as condições de trabalho degradantes. Verificamos que, conforme pesquisa de Bezerra, Silva, Maribondo, e Pinto (2011), os processos de trabalho vigentes configuram elementos que geram acometimento à saúde dos motoristas, dentre os quais, a sobrecarga de trabalho, notadamente devido à sobreposição de tarefas de motorista e de cobrador, bem como em virtude da ausência de tempo e de local adequado para a realização de refeições, favorecendo à prevalência de maus hábitos alimentares entre esses profissionais.

Ainda acerca do local de trabalho, Alquimim et al. (2012) registraram aspectos bem particulares no exercício dessa profissão, haja vista que, diferentemente de outros profissionais, que exercem sua atividade em locais fechados, climatizados e relativamente confortáveis, os motoristas de ônibus o fazem em ambiente público: o trânsito. Eles não possuem um local restrito e bem definido para a realização de suas tarefas, mas, ao contrário, trabalham fora dos portões da empresa, estando sujeitos a intempéries, tais como: o clima, - trajeto e as condições das vias, as condições de tráfego, a falha nos equipamentos e a pressão no cumprimento dos horários, dentre outros. Já na Revisão de Literatura, realizada por Almeida (2002), a respeito das condições de trabalho dos motoristas de ônibus, dentre os principais fatores externos que influenciam no desempenho dos motoristas de ônibus estão: exigências dos usuários, condições do tempo, condições das estradas, congestionamentos, poluições sonora e visual, viagens longas, temperatura do motor e iluminação deficiente.

Note-se que atentar para as condições de trabalho é de importância elementar. Dejours (2015) aponta que as condições de trabalho constituem os aspectos físicos, químicos e biológicos presentes no ambiente de trabalho, estando, dentre estas, a temperatura e as vibrações, por exemplo. Por condições biológicas, entendem-se as relacionadas com o ambiente dos vírus, bactérias; enquanto que, por condições químicas são considerados os vapores e as poeiras presentes no ambiente de trabalho. Note-se que tais condições de trabalho atacam, sobretudo, o corpo do trabalhador e sua saúde física. Essa relação entre trabalho e corpo é demonstrada, por exemplo, na pesquisa de Battiston, Cruz, e Hoffmann (2006), na qual, os elementos mais citados como causadores de fadiga - falta de conforto do assento, espaço restrito da cabine, linhas com maior número de paradas para embarque e desembarque de passageiros, incômodo do ruído causado pela localização do motor, do tráfego ou dos próprios passageiros - estão relacionados ao uso de medicamentos para dores: de cabeça, nas pernas e/ou nos braços, e na musculatura corporal como um todo.

Dejours (2015) alerta, ainda, para o fato de que aquilo que se passa no corpo das pessoas não está isolado do que se passa em seu psiquismo. Assim, todo potencial dano à integridade física dos trabalhadores é um potencial dano ao equilíbrio psíquico, e vice-versa. Em contrapartida, atentar para os aspectos 
relativos à organização do trabalho (Dejours, 2015) é também urgente e incontornável, uma vez que esta age insidiosamente, tendo, como alvo privilegiado, o funcionamento psíquico dos trabalhadores. A esta dimensão, dizem respeito elementos do processo de trabalho, tais como: a divisão do trabalho, o conteúdo das tarefas, as divisões entre as pessoas, as relações hierárquicas, a duração da jornada, a pressão por metas, a existência e a duração de intervalos, dentre outros aspectos.

Nos artigos analisados, as condições e organização do trabalho dos motoristas caracterizam-se pelos seguintes aspectos: a má conservação das vias, a ausência de um ponto de apoio para uso do banheiro, a falta de descanso entre uma viagem e outra (M. M. Costa et al., 2011; Pinto \& Neves, 2009), bem como pela inexistência de ajuste ergonômico correspondente às necessidades desses trabalhadores (Vellozo, 2010). Dessa forma, o modo como o trabalho está organizado e as condições em que deve ser exercido fazem parte de um conjunto denominado de Trabalho Prescrito.

Isso posto, Brito (2009) identifica que o sentido de trabalho prescrito está atrelado: (i) a uma forma de antecipação necessária e verificada em todos os processos produtivos; (ii) às condições dadas, as quais se relacionam aos componentes externos, considerando que algumas vezes esse ambiente representa um constrangimento na realização da tarefa e por isso, são apontados como integrantes da tarefa; (iii) às normas antecedentes, cuja conceituação está vinculada a uma forma de antecipação que se configura em um patrimônio coletivo, pertencente aos saberes técnicos, científicos e culturais, historicamente incorporados ao fazer, tais como códigos organizacionais ligados à divisão (social e sexual) do trabalho e às relações de poder, de exploração econômica e de dominação. Sinalizam aos valores do bem comum como saúde, educação, igualdade, presentes em uma dada sociedade, sobre os quais há sempre um campo de lutas, apontando, portanto, uma dimensão sócio-políticojurídica. Diante disso, as condições de trabalho constituem importante parcela das prescrições do trabalho dos motoristas de ônibus.

Nesse particular, além de apresentarem condições de trabalho tão degradadas e degradantes, os processos de trabalho vigentes no ofício de conduzir ônibus - jornadas de trabalho, pausas, salários, pressões para cumprimento de horários, movimentos repetitivos, etc. - configuram uma organização do trabalho com repercussões à saúde dos motoristas (Bezerra et al., 2011). Dentre esses, encontram-se referências à sobrecarga de trabalho, como é o caso da sobreposição das tarefas de condutor e cobrador, por exemplo: podemos destacar que, em nossas investigações na literatura acadêmica, não encontramos estudos atinentes aos efeitos e as implicações dessa dupla função. De acordo com Gianasi e Borges (2009), essa atividade profissional envolve uma multiplicidade de fatores, como, por exemplo: o controle do tempo das viagens, o controle das solicitações dos usuários, e a intensidade das jornadas. Tais 
fatores exigem mais tempo de trabalho desses profissionais, sendo, ainda fontes de desgaste, geradores de exaustão por sobrecarga, bem como contribuem para o desenvolvimento da síndrome de burnout e para seus consequentes danos, a curto, médio e longo prazo.

No que diz respeito ao conteúdo da tarefa, a relação com a saúde, em particular no referente à saúde mental, se torna evidente: pesquisas demonstram, por exemplo, que engarrafamentos e o comportamento de outros veículos geram irritação, requerendo o aumento da velocidade em outros trechos, como compensação para o tempo perdido nos engarrafamentos, fenômeno esse, corroborado por outra pesquisa (Battiston et al., 2006; A. V. Silva \& Günther, 2005). Já no que diz respeito às relações entre trabalhadores, as existentes entre motoristas e fiscais - responsáveis pelo controle do trabalho são mais instáveis do que entre os próprios pares, sendo comuns conflitos entre aqueles. Prange (2011), tomando o ponto de vista da gerência, verifica que, aos olhos dessa administração, os motoristas necessitam de alguém que os controle, vigie e puna, pois seriam dotados de tendências agressivas e impulsivas. A partir de seu ponto de vista, seriam os inspetores, aqueles que conseguiriam garantir a regularidade do serviço prestado, haja vista serem os responsáveis por observar, controlar e corrigir (punir?) o trabalho e o comportamento dos motoristas de ônibus e cobradores. Note-se, aqui, que, mediante a utilização de tais expedientes, se reforça a relação conflituosa existente entre condutores e fiscais, já apontada.

\section{Violência no trabalho}

As situações violentas tratam-se de condições de tensão vivenciada, nesse caso, pelos trabalhadores de transporte coletivo, sendo, frequentemente, citadas nas pesquisas, embora poucas publicações brasileiras sejam dedicadas ao tema: investigam, sobretudo, os efeitos dos assaltos a ônibus no cotidiano de trabalho, ainda que a violência vivenciada, nesse contexto, não se restrinja a assaltos, sendo também relatadas agressões físicas e verbais por parte dos usuários e de condutores de outros veículos, por exemplo.

Nesse particular, um artigo demonstra que o assalto, "fator traumático extremo", pode ou não desencadear o transtorno de estresse pós-traumático (TEPT) em rodoviários (Alves \& Paula, 2009). Entre trabalhadores vitimados por assaltos, é possível se perceber sintomas isolados do diagnóstico de TEPT, tais como: revivência da experiência em pensamentos, imagens, sonhos; sofrimento psicológico decorrente do contato com indícios externos que recordam algum aspecto do trauma; evitação de pessoas que lembrem o trauma; insônia e irritabilidade. Em outros dois artigos sobre os modos como motoristas e cobradores percebem e enfrentam a violência dentro de ônibus na cidade de Salvador, Bahia (Paes-Machado \& Levenstein, 2002, 2004), caracterizam-se os assaltos, os assaltantes, as estratégias dos trabalhadores para se protegerem 
dos roubos e as consequências dos assaltos na atividade destes profissionais. Além disso, são descritos os dois tipos de crimes enfrentados pelos trabalhadores: os assaltos em terminais e os ocorrentes nas corridas. Os criminosos, naquela cidade, tinham o seguinte 'perfil': jovens pobres e desempregados, do sexo masculino, com idade média de 21 anos.

Diante de tal conjuntura, os trabalhadores desenvolveram estratégias para lidar com essas situações: sinalizar, para colegas ou policiais, a presença de assaltantes e "não pegar passageiros suspeitos". Essa última estratégia, segundo os pesquisadores, reforça, e é reforçada, por preconcepções sobre jovens negros e mulatos. Algumas das consequências observadas, em virtude dos assaltos, foram: lesões fatais e não fatais, produção de medo, conflitos de identidade, tensões com os passageiros e conflitos trabalhistas referentes ao pagamento dos valores roubados.

\section{A organização do tempo e a atividade de trabalho}

"Me perdoe a pressa - é a alma dos nossos negócios" (Sinal Fechado - Paulinho da Viola).

Outro aspecto evidenciado nas análises consideradas diz respeito ao nível de pressão para o cumprimento dos horários estabelecidos, o qual ganha destaque nos estudos de Bezerra et al. (2011), Caiafa (2002), M. M. Costa et al. (2011), Gianasi e Borges (2009), Pinto e Neves (2009) e Prange (2011), enfatizando o pouco tempo de pausa entre uma viagem e outra. Nessas pesquisas se verificou que a significativa ausência de tempo, inclusive para realização das refeições, favorece a prevalência de maus hábitos alimentares, nos profissionais, conforme indicado acima.

Note-se que a menção da variável tempo foi verificada em boa parte das publicações analisadas. Notadamente, o tempo, em sua dimensão cronológica, é frequentemente considerado na atividade profissional de motorista. Aliás, no caso específico dos motoristas de ônibus urbano, o tempo é o principal ingrediente dessa atividade, haja vista o que o serviço de transporte vende ser o deslocamento de um lugar para outro. O lucro chega quando as passagens são vendidas: quando os passageiros entram e pagam por seu lugar. Ou seja: o motorista só produz quando um determinado número de passagens é vendido em um dado período de tempo. É, justamente, sobre o tempo de trabalho que vai incidir, de forma mais direta, o controle do capitalista (Caiafa, 2002).

Pinto e Neves (2009), por outro lado, ao descreverem o fator tempo como elemento central na atividade desses trabalhadores, elucidam os debates de normas em jogo nessas situações de trabalho: demonstram que a gestão do tempo, diante dos equívocos da prescrição e das variabilidades enfrentadas, consiste em um debate de normas, inseridas em um universo de valores, que se dá em torno de exigências prescritas - conduzir um número mínimo de passageiros por viagem, sem atrasá-la - e valores não dimensionados - 
preservação da própria saúde e a cordialidade com os passageiros. As relações com os passageiros, ganham destaque, também, nas análises de Zamboni e Barros (2012).

Dessa forma, o rígido cumprimento dos horários se torna, assim, uma tarefa de significativa demanda ao profissional, reduzindo a possibilidade de pausas reais e de descanso. Note-se que esse último aspecto também foi observado em uma empresa pública de transporte coletivo (Brunoro, Sznelwar, Bolis, \& Abrahão, 2012): os autores identificaram que a excelência das operações não depende apenas das decisões organizacionais, mas, fundamentalmente, das cotidianas regulações dos trabalhadores, objetivando, assim, a eficácia do serviço. Entretanto, tais regulações se desenvolvem mediante consideráveis custos à saúde, sendo, continuamente, negligenciadas pelos gestores.

Relações entre comportamentos inadequados de um motorista de ônibus e as características do itinerário urbano, por sua vez, foram demonstradas por A. V. Silva e Günther (2005): verificaram que a frequência de comportamentos considerados inadequados está significativamente correlacionada ao tempo total despendido nas viagens com passageiros, em eventos do trânsito e no total de paradas do trajeto. Evidenciaram, ainda, que os comportamentos emitidos pelos trabalhadores são efeitos de situações do trabalho e não características intrínsecas dos modos de conduzir.

Isso posto, no entanto, não se esgota a discussão em torno do aspecto do tempo considerado, quanto aos efeitos que exerce na atividade. Em um artigo, que discute a influência tecnológica na evolução das condições ergonômicas no posto de trabalho, foi verificado que, com o passar das horas, as posturas dos trabalhadores tornam-se inadequadas, corolárias ao aumento da velocidade dos movimentos decorrentes de atrasos nos horários de paradas, nos pontos e terminais (Nascimento \& Gontijo, 2004). Foram também demonstradas percepções ambíguas, sendo relacionadas às inserções de sistemas tecnológicos no trabalho, como, por exemplo, a bilhetagem eletrônica e o uso de câmeras de monitoramento: os quais tendem a melhorar a qualidade de vida e a reduzir o comprometimento corporal, mas não chegam a ser suficientes no sentido de compensar a deterioração salarial e a intensificação do trânsito, dentre outros aspectos. Em decorrência disso, os trabalhadores se sentem menos valorizados profissionalmente, em comparação com situações anteriores.

Querido, Nogueira, Gama e Orlando (2012), em análise sobre a atividade e as condições de trabalho, observaram que a superlotação dos ônibus dificulta a visibilidade do trânsito que, aliada à necessidade de dar trocos em movimento, intensifica, consideravelmente, a possibilidade de acidentes. Vale salientar que essas mesmas relações também foram verificadas por Brunoro et al. (2012), apontando indícios de distúrbios psíquicos relacionados ao trabalho, particularmente decorrentes dos casos de assaltos. 
Outro tema pesquisado na Revisão de Literatura é o alusivo às questões de gênero concernentes a esta profissão, composta, em sua maioria, por homens: no conjunto de pesquisas sobre o tema, encontramos apenas uma delas referindo-se às peculiaridades de ser mulher motorista de ônibus (Vellozo, 2010). A autora destaca que algumas mulheres entrevistadas relataram o uso de medicamentos para a suspensão da menstruação, assim como a diminuição na ingestão de líquido, atitude em decorrência à falta de banheiros que elas poderiam utilizar ao final de cada viagem. Tratam-se, portanto, de condições de trabalho que repercutem, direta e especificamente, na saúde da mulher, inclusive no que tange ao aspecto ergonômico, pelo fato do ônibus ser uma máquina projetada por homens, para homens, cuja atividade de dirigi-lo é socialmente direcionada aos homens (Vellozo, 2010).

\section{DISCUSSÃO}

"Todo mundo tem direito à vida, todo mundo tem direito igual" (Rua da Passagem - Lenine).

Dos resultados já mencionados podemos extrair algumas considerações acerca do trabalho dos motoristas de ônibus e sobre seus efeitos nesses profissionais: (i) o ofício se desenvolve em condições de trabalho que contribuem para hábitos de vida que intensificam os riscos de doenças coronarianas; (ii) a longa jornada contribui para dores osteomusculares, sendo mais frequentes nessa do que em outras profissões; (iii) ocorre perda auditiva correlacionada: à vibração de corpo inteiro, ao nível do ruído e à extensão da jornada de trabalho; e (iv) a ocorrência também dos distúrbios do sono, evidenciados entre os motoristas de ônibus interestaduais, os quais também contribuem para riscos de DCV. Já no que tange aos problemas relacionados a aspectos psíquicos da saúde, as poucas pesquisas realizadas sobre o tema não permitem apresentar evidências suficientes sobre o assunto, mas foram frequentemente apontados níveis consideráveis de estresse e a ocorrência da síndrome de burnout, e de queixas frequentes relacionadas à violência, problema que merece maior investigação.

Verificamos que em muitas pesquisas diversos aspectos organizacionais investigados, entre os quais a jornada de trabalho, a disponibilidade de pausas para alimentação e descanso ou o controle do horário da viagem apresentaramse associados a efeitos deletérios como comportamentos indesejados do condutor e queixas em relação à saúde, como a hipertensão. Por outro lado, verificamos também que foram observados efeitos positivos do trabalho nos processos de subjetivação dos trabalhadores, tais como o desenvolvimento de competências e de sentidos sobre o trabalho. Assim, embora os estudos epidemiológicos estabeleçam nexos entre a profissão e seus respectivos agravos à saúde, consideramo-los parcialmente limitados, já que não contemplam, em 
suas pesquisas, a dinamicidade do trabalho e a não submissão passiva dos trabalhadores às condições em que se inserem (Bendassolli, 2011; Brito, 2004).

Por outro lado, as pesquisas realizadas não permitem elencar, suficientemente, meios e perspectivas de ação para que tais problemas venham a ser enfrentados, até porque se verifica incompleta a abordagem das dimensões do trabalho nos seus delineamentos. Ademais, percebemos que uma concepção de saúde que se aproxima das perspectivas da Saúde Ocupacional, fartamente ancoradas em verificações de causalidades entre doenças e fatores de riscos, tende a fortalecer as perspectivas tradicionais daquilo que, em Psicodinâmica do Trabalho, denomina-se preventivismo (Cru \& Dejours, 1987): lógica clássica do campo da prevenção de acidentes que não tem levado a uma redução efetiva do quadro nocivo e que se sustenta em medidas técnicas de prevenção, sendo essas realizadas ou indicadas por especialistas que não consideram, por vezes, os próprios saberes de prudência desenvolvidos pela trajetória do ofício, em atividades concretas do trabalho.

Essa lógica - em sintonia com uma tradição na qual a prevenção da saúde é apreendida como resultante da conscientização da população (T. D. Moraes, 2011) e muitas vezes é atravessada por um viés prescritivo (Santorum, 2006) pode contribuir para que as ações de prevenção se restrinjam a políticas de vigilância e de treinamento de comportamentos e hábitos profissionais e de vida, previamente definidos como saudáveis, individualizados e desconectados das situações reais de trabalho. Isso se dá, sobretudo, porque poucas pesquisas se interessam pelas dimensões da atividade de trabalho e suas relações com processos de formação e desenvolvimento profissional.

Essas práticas, que, segundo Caponi (2003), visam normalizar condutas mais do que transformar condições perversas de existência, individualizam os processos de adoecimento, bem como podem produzir sentimentos de culpabilização por suas mazelas, além de poucas possibilidades de mudanças na vida concreta. Isso se comprova quando observamos que a única pesquisa sobre formação profissional, entre esses trabalhadores, e que discute modelos de intervenção no trabalho, trata de treinamento de preparação física para o ofício, ou seja, objetivando tornar os trabalhadores mais resistentes às exigências do trabalho (Zavanela et al., 2012). Além disso, poucos textos analisados sugerem que o trabalho dos motoristas de ônibus pode ser, também, uma possibilidade de produção de saúde ou de modos de vida, em sua positividade.

Dessa forma, quando analisadas, nas pesquisas, as diferentes dimensões do trabalho, tais como a atividade, a organização e as condições de trabalho, são apreendidas como variáveis independentes. Por outro lado, pautando-se mediante uma perspectiva distinta das acima mencionadas, e por outras questões sobre o trabalho, destacamos as contribuições da Ergonomia da Atividade e da Ergologia: nessa linhagem de pesquisa a experiência do trabalho é sempre reconfigurada pelos trabalhadores, requerendo sua apreensão como 
experiência de trabalhar, daí sua positividade (Falzon, 2007; Schwartz \& Durrive, 2010). Assim, a experiência do trabalho é compreendida como meio possível de produção de saúde, mesmo que se verifique, frequentemente aí, o fracasso dessa possibilidade, ou seja: o adoecimento (Schwartz \& Durrive, 2010).

A possibilidade de apreensão do trabalho a partir de sua positividade aponta para um terreno controverso de criação, onde o adoecimento não é a única possibilidade de viver essa realidade. Por outro lado, o cotidiano laboral também pode ser vivido como um exercício frustrado de um coletivo que não consegue fazer frente à organização do trabalho. Nesse caso, trata-se de, não apenas, se entender o processo de engendramento do adoecer, mas também o do não adoecer, mais até do que identificar exclusivamente a distribuição epidemiológica de sofrimento entre pares.

Sendo assim, observamos uma necessidade de desenvolvimento de pesquisas com esses trabalhadores em vários aspectos ainda pouco investigados, no país. Entre eles, necessitam-se mais pesquisas sobre: (i) lombalgia; (ii) distúrbios mentais e fadiga; (iii) efeitos dos acidentes e assaltos nos usuários desse transporte coletivo; (iv) relações entre violência e essa profissão; (v) relações entre processos de saúde-doença e coletivo de trabalho; (vi) efeitos da nova modalidade na profissão, que congrega o cargo de condutor e cobrador ao mesmo tempo; (vii) saberes profissionais e processos de formação; (viii) políticas públicas direcionadas para esses trabalhadores; assim como (ix) os possíveis efeitos de tais políticas. Vale ainda salientar que esses temas podem contribuir para estratégias mais eficazes, no que tange à melhoria da saúde desses profissionais, bem como dos serviços por eles prestados.

Diante desse contexto, verificamos a necessidade de uma reconfiguração nos desenhos investigativos, em particular, naqueles alusivos à inclusão de outros elementos das condições de trabalho, também ainda pouco investigados nos estudos epidemiológicos; a inclusão de aspectos econômicos, coletivos, culturais e políticos, já que estão quase ausentes nessas pesquisas; análises sobre os efeitos positivos/produtivos desse ofício para os profissionais; assim como verificamos a necessidade de mais investigações sobre as relações entre trabalho, subjetividade e transtornos mentais, privilegiando aspectos mais específicos do trabalho, tais como relações coletivas e hierárquicas, sentidos do trabalho, dentre outros. Sugerimos, inclusive, ampliação de estudos sobre a atividade de trabalho, que permitam desenhos de estratégias de desenvolvimento do ofício que considerem a não passividade dos trabalhadores e a importância do coletivo nas transformações da realidade de trabalho.

Nesse sentido, observamos que se fala sobre o motorista, mas pouco com o motorista: se faz necessário lhe dar voz e a possibilidade do exercício dessa profissão mediante o ponto de vista de quem a executa. Para tanto, propomos a realização de mais estudos, pautados numa relação dialógica entre pesquisadores e trabalhadores, considerando um processo de coanálise, no qual 
os motoristas ocupem também o lugar de analistas do seu trabalho, propriamente dito.

\section{CONSIDERAÇÕES FINAIS}

Todos os dias, milhares de pessoas circulam de ônibus pelas ruas das cidades. Realidades diversas contidas em uma mesma viagem. Não seria possível saber, um a um, de onde vêm, para onde vão. Mas é possível se afirmar que o ponto de partida de quem dirige o ônibus começa, muito antes, do virar a chave na ignição. Nesse sentido, as considerações apresentadas nos permitem inferir que é acidentado e repleto de obstáculos o caminho de motoristas de ônibus. E sujeito a acidentes. Tais considerações reafirmam coerência com os referenciais teóricos que contribuem para a compreensão de que não há trabalho simples: todo trabalho é complexo.

Sendo assim, podemos afirmar que transformações nesse contexto de trabalho devem ocorrer sem que se almeje a aplicação de modelos idealizados que garantiriam, incondicionalmente, a saúde e a produtividade. Mais que um final predeterminado, é a possibilidade de fazer diferentemente diante dos sofrimentos que se deve garantir. Isso se dá, inclusive, devido à riqueza do percurso, da viagem, do trajeto, dos viajantes, do condutor.... Importante é o meio do caminho e, sobretudo, o caminhar!

\section{REFERÊNCIAS}

Almeida, N. D. V. (2002). Contemporaneidade $x$ trânsito reflexão psicossocial do trabalho dos motoristas de coletivo urbano. Psicologia: Ciência e Profissão, 22(3), 62-69. doi:10.1590/S1414-98932002000300010

Almeida, N. D. V. (2010). Considerações acerca da incidência do estresse em motoristas profissionais. Revista de Psicologia, 1(1), 75-84.

Alquimim, A. F., Barral, A. B. C. R., Gomes, K. C., \& Rezende, M. C. (2012). Avaliação dos fatores de risco laborais e físicos para doenças cardiovasculares em motoristas de transporte urbano de ônibus em Montes Claros (mg). Ciência \& Saúde Coletiva, 17(8), 2151-2158. doi: $10.1590 /$ S1413-81232012000800025

Alves, C. R. S., \& Paula, P. P. (2009). Violência no trabalho: Possíveis relações entre assaltos e TEPT em rodoviários de uma empresa de transporte coletivo. Cadernos de Psicologia Social do Trabalho, 12, 35-46.

Balbinot, A., \& Tamagna, A. (2002). Avaliação da transmissibilidade da vibração em bancos de motoristas de ônibus urbanos: Um enfoque no conforto e na saúde. Revista Brasileira de Engenharia Biomédica, 18(1), 31-38. 
Battiston, M., Cruz, R. M., \& Hoffmann, M. H. (2006). Condições de trabalho e saúde de motoristas de transporte coletivo urbano. Estudos de Psicologia (Natal), 11, 333-343. doi:10.1590/S1413-294X2006000300011

Bendassolli, P. F. (2011). Mal estar no trabalho: Do sofrimento ao poder de agir. Revista Mal Estar e Subjetividade, 11(1), 65-99.

Benvegnú, L. A., Fassa, A. G., Facchini, L. A., \& Breitenbach, F. (2008). Prevalência de hipertensão arterial entre motoristas de ônibus em Santa Maria, Rio Grande do Sul. Revista Brasileira de Saúde Ocupacional, 33(118), 32-39. doi:10.1590/S0303-76572008000200004

Bezerra, S. M., Silva, E. F., Maribondo, J. d. F., \& Pinto, F. d. M. (2011). A influência das condições e organização do trabalho sobre a saúde de motoristas. TEMA - Revista Eletrônica de Ciências, 11(16).

Bréder, V. F., Dantas, E. H. M., Silva, M. A. G., \& Barbosa, L. G. (2006). Lombalgia e fatores psicossociais em motoristas de ônibus urbano. Fitness \& Performance Journal, 5(5), 295-299. doi:10.3900/fpj.5.5.295.p

Bréder, V. F., Oliveira, D. F., Dantas, E. H. M., \& Silva, M. A. G. (2006). Prevalência de lombalgia em motoristas de ônibus urbano. Fisioterapia Brasil, 7(4), 290-294.

Brito, J. (2004). Saúde do trabalhador: Reflexões a partir da abordagem ergológica. In M. Figueiredo, M. Athayde, J. Brito, \& D. Alvarez (Orgs.), Labirintos do trabalho: Interrogações e olhares sobre o trabalho vivo (pp. 91-114). Rio de Janeiro, RJ: DP\&A.

Brito, J. (2009). Trabalho prescrito. In I. B. Pereira, \& J. C. F. Lima (Orgs.), Dicionário da educação profissional de saúde (pp. 440-453). Rio de Janeiro, RJ: Fiocruz, MS.

Brunoro, C., Sznelwar, L. I., Bolis, I., \& Abrahão, J. (2012). Contributions of ergonomics to the construction of bus drivers health and excellence in public transport and at work. Work: A Journal of Prevention, Assessment and Rehabilitation, 41(0), 30-35. doi:10.3233/WOR-2012-0131-30

Caiafa, J. (2002). Jornadas urbanas: Exclusão, trabalho e subjetividade nas viagens de ônibus na cidade do Rio de Janeiro. Rio de Janeiro, RJ: FGV.

Câmara, A. M., Bevilaqua, A. D., \& Moraes, M. F. (2008). A influência do uso de um apoio para coluna lombar sobre a lombalgia e ciatalgia em motoristas de ônibus. Revista Terapia Manual, 6(24), 70-74.

Caponi, S. (2003). A saúde como abertura ao risco. In D. Czeresnia, \& C. M. Freitas (Orgs.), Promoção da saúde: Conceitos, reflexões, tendências (pp. 55-77). Rio de Janeiro, RJ: Editora Fiocruz.

Carneiro, L. R. V., Coqueiro, R. S., Freire, M. O., \& Barbosa, A. R. (2007). Sintomas de distúrbios osteomusculares em motoristas e cobradores de ônibus. Revista Brasileira de Cineantropometria \& Desempenho Humano, 9(3), 277-283. 
Cepinho, P. C., Corrêa, A., \& Bernardi, A. P. A. (2003). Ocorrência de perda auditiva em motoristas de ônibus e caminhões de São Paulo. Revista CEFAC, 5, 181-186.

Chaves, D. B. R., Costa, A. G. de S., Oliveira, A. R. de S., Oliveira, T. C., Araujo, T. L., \& Lopes, M. V. O. (2008). Fatores de risco para hipertensão arterial: Investigação em motoristas e cobradores de ônibus. Revista de Enfermagem da UERJ, 16(3), 370-376.

Corrêa Filho, H. R., Costa, L. S., Hoehne, E. L., Pérez, M. A. G., Nascimento, L. C. R., \& Moura, E. C. (2002). Perda auditiva induzida por ruído e hipertensão em condutores de ônibus. Revista de Saúde Pública, 36, 693701. doi: 10.1590/S0034-89102002000700006

Costa, L. B., Koyama, M. A. H., Minuci, E. G., \& Fischer, F. M. (2003). Morbidade declarada e condições de trabalho: O caso dos motoristas de São Paulo e Belo Horizonte. São Paulo em Perspectiva, 17, 54-67. doi:10.1590/S010288392003000200007

Costa, M. M., Mastroeni, S. S. B. S., Reis, M. A. M., Erzinger, G. S., \& Fabio, M. M. (2011). Excesso de peso em motoristas de ônibus da rede urbana. Revista Brasileira de Ciência e Movimento, 19(1), 42-51. doi: $10.18511 / \mathrm{rbcm} . v 19 i 1.1828$

Cru, D., \& Dejours, C. (1987). Saberes de prudência nas profissões da construção civil: Nova contribuição da psicologia do trabalho à análise da prevenção de acidentes na construção civil. Revista Brasileira de Saúde Ocupacional, 15(59), 30-34.

Dejours, C. (2015). A loucura do trabalho (5. ed. rev.). São Paulo, SP: CortezOboré.

Falzon, P. (Org.). (2007). Ergonomia. São Paulo: Edgar Blucher .

Faria, B. K., Amorim, G., \& Vancea, D. M. M. (2007). Perfil alimentar e antropométrico dos motoristas de ônibus da empresa de transporte coletivo Jotur/Palhoça - SC. Revista Brasileira de Obesidade, Nutrição e Emagrecimento, 1(1), 11-20.

Freitas, R. G. F., \& Nakamura, H. Y. (2003). Perda auditiva induzida por ruído em motoristas de ônibus com motor dianteiro. Saúde em Revista, 5(10), 13-19.

Gianasi, L. B. S., \& Borges, L. O. (2009). Síndrome de burnout no setor de transporte de Natal. Psicologia: Teoria e Pesquisa, 25, 297-305. doi: 10.1590/S0102-37722009000300003

Gonçalves, J., \& Buaes, C. S. (2011). Sentidos do trabalho e do afastamento por problemas de saúde mental para motoristas de transporte coletivo urbano: Um estudo de caso. Cadernos de Psicologia Social do Trabalho, 14(2), 195210. doi:10.11606/issn.1981-0490.v14i2p195-210

Guérin, F., Laville, A., Daniellou, F., Duraffourg, J., \& Kerguelen, A. (2001). Compreender o trabalho para transformá-lo: A prática da ergonomia. São Paulo, SP: Edgar Blücher. 
Guterres, A., Duarte, D., Siqueira, F. V., \& Silva, M. C. (2011). Prevalência e fatores associados a dor nas costas dos motoristas e cobradores do transporte coletivo da cidade de Pelotas-RS. Revista Brasileira de Atividade Física \& Saúde, 16(3), 240-245. doi:10.12820/RBAFS.V.16N3P240-245

Hirata, R. P., Sampaio, L. M., Leitao Filho, F. S., Braghiroli, A., Balbi, B., Romano, S., . . ., \& Oliveira, L. V. (2012). General characteristics and risk factors of cardiovascular disease among interstate bus drivers. Scientific World Journal, 2012, 216702. doi:10.1100/2012/216702

Junior, É. A. S. (2003). De que adoecem e morrem os motoristas de ônibus? Uma revisão da literatura. Revista Brasileira de Medicina do Trabalho, 1(2), 138-147.

Lacerda, A., Figueiredo, G., Neto, J. M., \& Marques, J. M. (2010). Achados audiológicos e queixas relacionadas à audição dos motoristas de ônibus urbano. Revista Brasileira da Sociedade de Fonoaudiologia, 15(2), 161-166. doi: 10.1590/S1516-80342010000200003

Landim, M. B. P., \& Victor, E. G. (2006). Escore de Framingham em motoristas de transportes coletivos urbanos de Teresina, Piauí. Arquivos Brasileiros de Cardiologia, 87, 315-320. doi:10.1590/S0066-782X2006001600014

Ledesma, R., Peltzer, R., \& Poó, F. (2008). Análisis de la producción en psicología del tránsito mediante PsyciNFO (2000-2006). Psic: Revista da Vetor Editora, 9(1), 11-24.

Macedo, C. S. G., \& Battistella, L. R. (2007). Impacto da lombalgia na qualidade de vida de motoristas de ônibus urbanos. Arquivo de Ciências em Saúde Unipar, 11(3), 163-167.

Martins, A. L., Alvarenga, K. F., Bevilacqua, M. C., \& Filho, O. A. C. (2001). Perda auditiva em motoristas e cobradores de ônibus. Revista Brasileira de Otorrinolaringologia, 67(4), 467-473.

Martins, P. J., D'Almeida, V., Vergani, N., Perez, A. B., \& Tufik, S. (2003). Increased plasma homocysteine levels in shift working bus drivers. Occupational Environmental Medicine, 60(9), 662-666. doi: $10.1136 /$ oem.60.9.662

Mello, M. T., Santana, M. G., Souza, L. M., Oliveira, P. C. S., Ventura, M. L., Stampi, C., \& Tufik, S. (2000). Sleep patterns and sleep-related complaints of Brazilian interstate bus drivers. Brazilian Journal of Medical and Biological Research, 33(1), 71-77. doi:10.1590/S0100-879X2000000100010

Moraes, G. N., \& Fayh, A. P. T. (2011). Avaliação nutricional e fatores de risco cardiovascular em motoristas de transporte coletivo urbano. Cadernos de Saúde Coletiva, 19(3), 334-340.

Moraes, T. D. (2011). Positividade do risco e saúde: Contribuições de estudos sobre trabalho para a saúde pública. Trabalho, Educação e Saúde, 9(3), 399-430. doi:10.1590/S1981-77462011000300004 
Nascimento, I. B., \& Gontijo, L. A. (2004). Evolução das condições ergonômicas no posto de trabalho do motorista de ônibus urbano. Fisioterapia Brasil, 66.

Neri, M., Soares, W. L., \& Soares, C. (2005). Condições de saúde no setor de transporte rodoviário de cargas e de passageiros: Um estudo baseado na pesquisa nacional por amostra de domicílios. Cadernos de Saúde Pública, 21, 1107-1123. doi:10.1590/S0102-311X2005000400013

Neto, J. F., Barreto, A. C., Sá, V. W., \& Maini, R. M. D. (2008). Análise comparativa da prevalência de lombalgia entre motoristas de ônibus de turismo e coletivo urbano. Novo Enfoque, 6(6), 1-13.

Oliveira, A. C. F., \& Pinheiro, J. Q. (2007). Indicadores psicossociais relacionados a acidentes de trânsito envolvendo motoristas de ônibus. Psicologia em Estudo, 12, 171-178. doi:10.1590/S1413-73722007000100020

Paes-Machado, E., \& Levenstein, C. (2002). Assaltantes a bordo: Violência, insegurança e saúde no trabalho em transporte coletivo de Salvador, Bahia, Brasil. Cadernos de Saúde Pública, 18(5), 1215-1227. doi:10.1590/S0102$311 \times 2002000500014$

Paes-Machado, E., \& Levenstein, C. (2004). I'm sorry everybody, but this is Brazil: Armed robbery on the buses in Brazilian cities. British Journal of Criminology, 44, 1-14. doi:10.1093/bjc/44.1.1

Pinto, F. d. M., \& Neves, M. Y. (2009). A gestão da atividade do motorista de ônibus: Um olhar ergológico. Estudos e Pesquisas em Psicologia, 9(2), 493511.

Prange, A. P. L. (2011). "Quem dá mais, cobra mais!" Uma análise das normas antecedentes do ofício de motorista de ônibus em um contexto específico. Estudos e Pesquisa em Psicologia, 11(2), 551-565.

Queiroga, M. R., \& Ferreira, S. A. (2005). Ocorrência de dor na coluna vertebral em motoristas de ônibus e bombeiros militares. UNOPAR Científica, Ciências Biológicas e Saúde, 7(1), 21-26. doi:10.17921/2447-8938.2005v7n1p\%25p Querido, A., Nogueira, T., Gama, R., \& Orlando, J. (2012). Ergonomic work analysis of urban bus drivers in Rio de Janeiro city. Work: A Journal of Prevention, Assessment and Rehabilitation, 41(0), 5956-5958. doi: 10.3233/WOR-2012-0993-5956

Rosenbloom, T. (2011). Professional drivers. In B. E. Porter (Org.), Handbook of traffic psychology (pp. 389-399). San Diego, CA: Elsevier.

Sampaio, R. F., Coelho, C. M., Barbosa, F. B., Mancini, M. C., \& Parreira, V. F. (2009). Work ability and stress in a bus transportation company in Belo Horizonte, Brazil. Ciência \& Saúde Coletiva, 14, 287-296. doi: 10.1590/S1413-81232009000100035

Santorum, K. (2006). Pelas fendas do trabalho vivo: Textos, contextos e atos na atividade de vigilância em saúde do trabalhador. (Doutorado), Fiocruz, Rio de Janeiro. 
Santos, A. S., \& Júnior, N. C. (2009). Audiometria de tronco encefálico em motoristas de ônibus com perda auditiva induzida pelo ruído. Brazilian Journal of Otorhinolaryngology, 75(5), 753-759. doi:10.1590/S180886942009000500023

Santos, E. H. R., Mello, M. T., Pradella-Hallinan, M., Luchesi, L., Pires, M. L. N., \& Tufik, S. (2004). Sleep and sleepiness among brazilian shift-working bus drivers Chronobiology International, 21(6), 881-888. doi:10.1081/CBI200035952

Schwartz, Y., \& Durrive, L. (Orgs.). (2010). Trabalho e ergologia: Conversas sobre a atividade humana. Niterói, RJ: Eduff.

Silva, A. V., \& Günther, H. (2005). Características de itinerário urbano e comportamentos inadequados de um motorista de ônibus. Psicologia: Pesquisa e Trânsito, 1, 33-43.

Silva, L. F., \& Mendes, R. (2005). Exposição combinada entre ruído e vibração e seus efeitos sobre a audição de trabalhadores. Revista de Saúde Pública, 39(1), 9-17. doi:10.1590/S0034-89102005000100002

Siviero, A. B., Fernandes, M. J., Lima, J. A. C., Santoni, C. B., \& Bernardi, A. P. A. (2005). Prevalência de perda auditiva em motoristas de ônibus do transporte coletivo da cidade de Maringá - PR. Revista CEFAC, 7(3), 376381.

Souza, N. R. M., \& Silva, N. A. S. (2005). Exames admissionais e aposentadorias precoces em motoristas de ônibus: Influência da hipertensão arterial. Revista da SOCERJ, 18(2), 154-159.

Souza, N. R. M., \& Silva, N. A. S. (2006a). Comparação das características de motoristas de ônibus em relação à realização dos exames de bioquímica: Quando o silêncio pode afetar as conclusões. Revista da SOCERJ, 19(4), 313-317.

Souza, N. R. M., \& Silva, N. A. S. (2006b). Nível de atenção médica em uma população de motoristas de ônibus em relação a fatores de risco cardiovascular que tenham implicações trabalhistas. Revista da SOCERJ, 19(2), 148-155.

Souza, N. R. M., \& Silva, N. A. S. (2006c). Sensibilidade, especificidade, valor preditivo negativo e positivo, para o conhecimento da condição de hipertenso frente à medida pressórica, em motoristas de ônibus. Revista da SOCERJ, 19(1), 54-59.

Teixeira, M. L. P., \& Fischer, F. M. (2008). Acidentes e doenças do trabalho notificadas, de motoristas profissionais do estado de São Paulo. São Paulo em Perspectiva, 22(1), 66-78.

Vellozo, D. P. M. (2010). Mulheres ao volante: Uma análise de gênero, saúde e trabalho em mulheres motoristas de ônibus na cidade do Rio de Janeiro. (Doutorado Tese), Fiocruz, Rio de Janeiro. 
Viegas, C. A. A., \& Oliveira, H. W. (2006). Prevalência de fatores de risco para a síndrome da apnéia obstrutiva do sono em motoristas de ônibus interestadual. Jornal Brasileiro de Pneumologia, 32, 144-149. doi: $10.1590 /$ S1806-37132006000200010

Zamboni, J., \& Barros, M. E. B. d. (2012). Paradoxo do motorista de ônibus como passageiro: Subjetividade, atividade, videografia. Ecos: Estudos Contemporâneos da Subjetividade, 2(2), 319-331.

Zavanela, P. M., Crewther, B. T., Lodo, L., Florindo, A. A., Miyabara, E. H., \& Aoki, M. S. (2012). Health and fitness benefits of a resistance training intervention performed in the workplace. The Journal of Strength and Conditioning Research, 26(3), 811-817. doi: 10.1519/JSC.0b013e318225ff4d

Sobre os autores

Thiago Drumond Moraes é psicólogo pela Universidade Federal do Espírito Santo, mestre em psicologia pela Universidade Federal Fluminense e doutor em psicologia social pela Universidade do Estado do Rio de Janeiro. Trabalha na linha de Psicologia do Trabalho e Organizacional e recebe financiamento de pesquisa da Fapes. thiago.moraes@ufes.br

Katia Santorum é psicóloga pela Universidade Católica de Pelotas, mestre em Psicologia Social e da Personalidade pela PUC/RS e doutora em Saúde Pública pela Escola Nacional de Saúde Pública Sérgio Arouca - Fiocruz/RJ. Trabalha nas linhas de Políticas Públicas; Saúde, Subjetividade e Trabalho; Psicologia do Trabalho e Organizacional. katia.santorum@gmail.com

Fatima Valeria Belo de Souza é psicóloga pela Universidade do Estado do Rio de Janeiro, mestranda em Políticas Públicas e Formação Humana pela Universidade do Estado do Rio de Janeiro. Trabalha na linha Psicologia do Trabalho, Saúde e Subjetividade. Recebe financiamento de pesquisa da CAPES.

psifatimabelo@gmail.com

Laís Rocha Ávila é psicóloga pela Universidade Federal do Espírito Santo.

Trabalha com adolescentes que cometeram ato infracionais. Recebeu financiamento de pesquisa da Fapes. Ialaavila1@hotmail.com Stefane Stolze Vieira é psicóloga pela Universidade Federal do Espírito Santo.

Trabalha na área de assistência social. teastolze@gmail.com

Recebido em: 15/05/2016

Revisto em: 26/09/2016

Aceito em: $14 / 11 / 2016$ 